\title{
Hearing our Voices: Pathways from Oppression to Liberation through Community- Based Participatory Research
}

Dr Rita Dhungel ${ }^{+*}$ Shanti Lama, ${ }^{\tilde{i}}$ Auska Khadka, ${ }^{¥}$ Sharda K.C.,${ }^{¥}$ Mendo Sherpa, ${ }^{\ddagger}$ Pratima Limbu ${ }^{*}$, Ghaynu Limbu*, Monika Rai ${ }^{*}$ and Sweata Shrestha ${ }^{*}$

\section{Abstract}

A number of qualitative-based participatory approaches have been used to analyse and address structural inequalities and intersectional gender oppression. This has been broadly evident in the academic environment and, particularly, in social work education and practice. However, more participatory aspects of social justice research, such as inviting and supporting disenfranchised and vulnerable populations to become more intimately involved in identifying their issues, together with developing remedial strategies and acting upon them, are still generally marginal, leaving both researchers and practitioners travelling on the uneven ground. In an attempt to level these troughs in social work education (and, by extension, practice), the paper will explore the transformative outcomes associated with participatory action research conducted as emancipatory and liberatory tools in research undertaken in collaboration with trafficking survivors in Nepal. The purpose of this paper is to explore the collective experiences of growing critical consciousness around social injustice and structural inequalities that contributed to survivors being "doubly victimised". Hence, in this paper, their resiliency in the face of that victimisation is not discussed. The goal of the paper is three-fold: (1) share the study process/approaches that supported an increase in the survivors' critical thinking about their own oppression; (2) consider the impact of survivors' solidarity in social and political action; and (3) examine the applicability of an emerging model of survivors' liberatory practice. Overall, this paper will explore new and potentially liberatory ways to address the multiple and complex issues facing survivors upon return, and promote transformative praxis to support healthy individual and collective development.

Keywords: Collaborative Experiences, Critical Consciousness, Liberation, Oppression, Trafficking Survivors, Shakti Samuha, Community-Based Participatory Research, Nepal

\footnotetext{
${ }^{\dagger}$ Assistant Professor, Social Work, MacEwan University, 9-508B, City Centre Campus, 10700 - 104 Avenue Edmonton, AB780-497-5273, Canada

${ }^{*}$ Corresponding Author, Email: dhungelr@macewan.ca

íShanti Lama, Chairperson, Shanti Foundation, Email: shanti.foundations@gmail.com

${ }^{¥}$ Shakti Samuha, Nepal

(c) Dhungel et al. This is an Open Access article distributed under the terms of the Creative Commons Attribution License (http://creativecommons.org/licenses/by/2.0), which permits unrestricted use, distribution, and reproduction in any medium, provided the original work is properly cited.
} 


\section{Introduction}

The Sex Trafficking of women and children is a global social issue and a serious crime, which has gained widespread attention from a significant number of stakeholders, including the United Nations, academia, NGOs and INGOs, and national governments (Cameron \& Newman, 2008; Dhungel 2017d; Winterdyk, Perrin, \& Reichel, 2012). Generally, these players have challenged trafficking from preventative perspectives. While prevention is undoubtedly important, little focus has been given to the protection and support of trafficked women and children who eventually return to their home country, often with big hopes and high expectations (Dhungel, 2017d). To remedy this shortfall, a feminist researcher, Rita Dhungel, with the Faculty of Social Work, University of Calgary, who immigrated to Canada from Nepal in 2005, initiated a community-based participatory study to amplify the experiential voices of survivors in their reintegration and help them embark on their liberation paths. Subsequently, she approached Shakti Samuha in Nepal, the first organisation in the world created by trafficking survivors (Shakti Samuha, 2013), and expressed her desire to work with them in drawing attention to, and addressing, the complex and dynamic issues faced by survivors from both a human rights and social justice lenses.

The researcher initiated meetings with Board members of Shakti Samuha. During the meetings, the researcher shared the values and principles of Participatory Action Research (PAR) and its implications with a focus on its transformative nature. After learning of the research plan, the Board expressed their interest in helping with the study and advised the researcher to meet some survivors currently working with them and share the research plan and its nature. Subsequently, the first information session was scheduled where eight survivors were present. The session provided a brief introduction to PAR and outlined the roles and status of co-researchers in the study. In this session, it was clearly communicated that by using PAR as a liberatory tool, the researcher would be an ally who was recognised as a "researcher", and the trafficking survivors from Shakti Samuha would be partners, recognised as "peer researchers" and/or "co-researchers" if they chose to participate in this study. This inspired them to get involved in the study process, which will be discussed later in this paper. These partners worked collaboratively for a year, and PAR was used as a framework to examine the multifaceted experiences of trafficked women in their process of reintegration, through an action-reflectionaction process (Dhungel, 2017a, 2017b, 2017c, 2017d).

While developing this partnership, collaborative efforts promoting the democratic participation of each were established, and the egalitarian relationship between researcher and coresearchers, and the equal value of different forms of knowing were given considerable attention. To elaborate, upon asking the coresearchers if they were interested in sharing their experiences and being involved in the study, the co-researchers were excited but also expressed fear about their writing abilities in the Nepali language. The researcher (from Canada) and co-researchers (from Nepal) met on Skype and discussed what they wanted to share in the paper, and then developed the study's outline. The consensus on sharing their reflections first in Nepalese and later with the researcher translating them into English motivated the coresearchers to agree to be part of this partnership. The co-researchers started meeting in person regularly and explored their collective voices and experiences. In the meantime, the researcher was frequently contacted, through emails and Skype, for academic suggestions and insights.

Consequently, this paper is a blend of academic discourse and the lived knowledge and subjective experiences of the co-researchers. In this paper, with the permission of coresearchers, their stories were translated into 
English in the same manner as their original writing, and, to ensure integrity, later it was verbally shared with the co-researchers. Therefore, the term "we" used throughout this article refers only to co-researchers, and the term "research group" includes both the researcher and co-researchers. This paper is grounded in knowledge co-generated from the PAR process, and the voices and narratives the survivors collectively documented, shared and amplified. The group, for example, states:

We hardly get an opportunity to share our voices and explore our common experiences in a safe environment. Rita came as an ally and created a platform for us to critically understand our issues and move into actions to address the issues. Frankly speaking, we believe that this was our project and we worked hard to make this project meaningful, evocative and effective. Therefore, through this paper, we want to share our journey from oppression to liberation, especially what we did in solidarity and how we accomplished our goals.

The article begins with a brief literature review and a discussion of the theoretical framework. Consideration of the collaborative process that facilitated survivors coming together to advocate for their individual and collective rights will be highlighted. Following from this, an emerging liberation model designed for cooperative work with trafficking survivors (the " 4 Es" approach - Experience, Exposure, Engagement and Empowerment), based on a theoretical framework (Cordo \& Hill- Rodriguez, 2017; Wagaman, 2011; Winderdyk \& Dhungel, 2018), will be briefly discussed. This theoretical foundation is augmented by a practical examination of the journey from oppression to liberation. The paper concludes with a discussion and recommendations for advancing awareness of the social problem and provides suggestions for some potential, multifaceted solutions.

\section{Literature Review}

To solve the complex social and cultural issue of reintegration, it is important to critically understand the experiences of the trafficking survivors; however, the current literature is limited in providing information on the trafficking experience and the struggles of the post-trafficking period in the Nepalese context (Dhungel, 2017d). The trafficking survivors experience social exclusion and ostracism when they return to their home country, and the survivors are frequently rejected by their families, communities and society because of the high level of stigma attached to them (Buet, Bashfod \& Basnyat, 2012; Frederick, Basnyat \& Aguettant, 2010; Sharma, 2014). Women report being doubly victimised in the way they are treated in the rehabilitation and reintegration process (Dhungel, 2017b, 2017d).

Dhungel (2017d) noted that much of the information about human trafficking is collected in NGO and INGO publications. A considerable number of documents and reports are also prepared by the United Nations, which focuses on the causes, consequences and process of trafficking, together with policy recommendations and program development. Most knowledge has been created through the use of quantitative methodologies and analyses of secondary information from various sources, and only a few scholars have directly explored the reintegration experiences of trafficking survivors (Chaulagai, 2008; Chen \& Marcovici, 2003; Locke, 2010; McNeill, 2008, Sharma, 2014). However, research has yet to promote the value of involving survivors in research for social justice, and personal and social transformation.

Nepal has demonstrated a significant commitment to anti-trafficking efforts by developing national plans, laws, and policies, and a variety of other approaches, including preventive and protective measures such as the National Plan of Action against Trafficking in Persons, Trafficking in Women and Children 2012, and Human Trafficking and Transportation Control Act 2007. However, most of these anti- 
trafficking initiatives adopt a victim-centred approach that focus on prevention, but do not adequately address the aspirations of trafficking survivors upon reintegration into families, communities, and society (Buet, Bashford, \& Basnyat, 2012; Chaulagai, 2009; Chen \& Marcovici, 2003; Dhungel, 2017c, 2017d; Frederick, 2005; Hennink \& Simkhada, 2004; Sharma, 2014). For example, some reintegration programs including counselling, basic medical care services, educational and vocational training and preventing stigmatisation are more victim-centred, and seem to be pre-designed and generalised under a "one size fits all model" (Adhikari, 2011; Bohl, 2010; Chaulagai, 2009; Dhungel, 2017d; Sharma, 2014). Those who want some level of professional training, including health care and hotel management, as opposed to vocational training, such as sewing and knitting, are not provided with these enhanced opportunities, which can limit their economic opportunities and independence. Given the above limitations and challenges, the community-based participatory research project was initiated to not only provide survivors with an opportunity to understand their intersectional oppression but also to promote personal and social transformation, including agency, connectivity and hope.

\section{Theoretical Frameworks/Approaches}

Critical Social theories, including liberating education and critical consciousness (Freire, 1970), provide key theoretical foundations for this study. Critical theory recognises multiple realities, the numerous ways in which people who are oppressed find their voices, and the need for active solidarity between researchers and people who want to change oppressive societies (Agger, 2006; Depoy, Harman \& Haslet, 1999; Dominelli, 2002; Mullaly, 1997, 2010). Critical theory does not accept "prevailing ideas, actions and social condition as unchanging or immutable and also refuses to accept the existing rules of society, the boundaries of action and knowledge as natural and inevitable" (Hoffman, 1987, p. 233). The approach also argues that simply understanding and explaining issues of oppression is not sufficient; rather, all people impacted by the various and interconnected dimensions of oppression ought to be informing practice and suggesting actions for change (Depoy, Harman \& Haslet, 1999; Hoffman, 1987).

Liberating education, or popular education, a term first used by Paulo Freire in 1970, is a philosophy and learning process applied to advance personal and social transformation. Boal (1979) argued that liberating education promotes engagement with people who do not normally have opportunities to develop their critical consciousness as a means to individual and collective empowerment. Boal (1979) further asserted that empowerment is both a process and an outcome of the liberating process. Liberating education engages oppressed people with critical thinking and action directed towards their liberation. Sagris (2008:1) highlighted the purpose and outcomes of liberating education:

The goal of liberatory education is to provoke the student to question all taken-for-granted values, ideas, norms, beliefs, etc. of her experience that are the given presuppositions comprising the dominant social paradigm. The space this educational act opens up, as rupture, emancipates the learner from the domination of what has been taken-asgiven. This shift is neither a turn, reverse, nor a side track, but a permanent break with the power with which these presuppositions are deemed desirable and plausible. (p. 1).

Overall, liberating education and critical consciousness are strengths which provide marginalised populations with the means to become more intimately involved in a comprehensive analysis of their oppression for emancipation and liberation. As suggested by Antonio Gramsci, dominant groups can maintain power through a flexible blend of consent and coercion (Hoare \& Smith, 1999). Coercion can be seen in laws, together with the use of the police and armed forces to maintain order. Consent, 
however, is more subtle, and involves creating conditions of "hegemony" which set the boundaries of "common sense". This occurs largely through the cultural channels of society, such as religion, education and entertainment, and socially constructs the norms for "acceptable" discussion, values and beliefs. The challenge, therefore, is for oppressed groups to participate in the creation of a counterhegemonic alternative. This is not easy. As Dominelli (2002) argued false consciousness is promoted by a lack of understanding of the socio-economic environment, political structures and power of dominant populations, which perpetuates structural domination and hegemony (Dominelli, 2002; Freire, 1970; Mullaly, 2010; Park, 1993). Recognising this, critical theory is grounded in the notion of conscientisation, which suggests that people in oppression need to critically understand their oppression, and recognise that this oppression is not their fault (Mullaly, 2010), nor is it permanent. Such awareness can then serve as the foundation for the creation of a much needed counter-hegemonic alternative.

Given the study's purpose and objectives, PAR, as a community-based research approach, was selected as the most appropriate method for knowledge creation. PAR originated from the "action research" of Kurt Lewin, an American social psychologist (McTaggart, 1991). Lewin suggested that by working with those who practice in a field to generate information and knowledge, transformative impacts can be achieved. By engaging in co-operative inquiry with participants, PAR minimises the intellectual and ideological distance between participants and researchers and promotes inclusive group dynamics (Reason \& Bradbury, 2006). More importantly, this process changes the traditional "objective" role of the researcher to one of a "committed" co-investigator and/or facilitator, and the customary participant role as "informant" evolves to "co-researcher" in the research process (Herr \& Anderson, 2005). As noted by Fals-Borda (1979), action-reflectionaction (praxis) as a means of transformative impact is considered a liberation process in critical social science. For example, Fals-Borda (1988) claimed that PAR is "a complex process that includes adult education, situation analysis, critical analysis, and practice as sources of knowledge for understanding new problems, necessities and dimension of reality" (p. 85).

In this PAR study, female trafficking survivors, who met the following criteria, were invited to an information session and later participated in the collaborative journey:

- Were 18 years or older;

- Had been trafficked to India for sexual trade;

- Had returned from India to Nepal;

- Currently living for over two months or used to live in the shelter in Kathmandu after they returned from India.

Eight female participants, ranging from 24 to 40 years of age and who were born outside of Kathmandu, emerged as co-researchers and were involved in both the data creation and data analyses process. Out of eight, four coresearchers were married with children. Five were Hindus, and three were Buddhist. In this study, the data creation and collection methods were used as vehicles for meaningful dialogue, which provided survivors with an opportunity to develop their critical knowledge related to structural barriers to their reintegration. More importantly, this process helped them to share their voices and identify common experiences in their reintegration, and develop actions for both personal and social transformation through a number of different performative actions, including stakeholder interviews and street dramas. The process of data analysis began simultaneously with that of data creation and interpretation. All tape-recorded interviews and participants' group discussions were transcribed in Nepali, and then translated into English. In collaboration with the co-researchers, transcripts were then analysed to identify, verify, and clarify themes to ensure they authentically reflected the participants' views. Overall, data analysis took place in a participatory way at all stages so that the women could validate and provide ongoing feedback on 
the themes identified in the research process. Data analysis methods adhered to the requirements of the data creation method determined by the co-researchers. The coresearchers were significantly involved in the process of analysis by coding and categorising the data.

\section{Process and Tools for Liberation}

This section discusses the process that provided us with the opportunity to come together and work collaboratively. While reflecting on our journey, we recognised that we went through four different, yet interconnected and overlapping phases: (1) grounding context; (2) critically understanding the socio-political environment; (3) developing skills and constructing knowledge; and (4) sharing knowledge and moving into social, political and cultural action as demonstrated below in Figure 1.

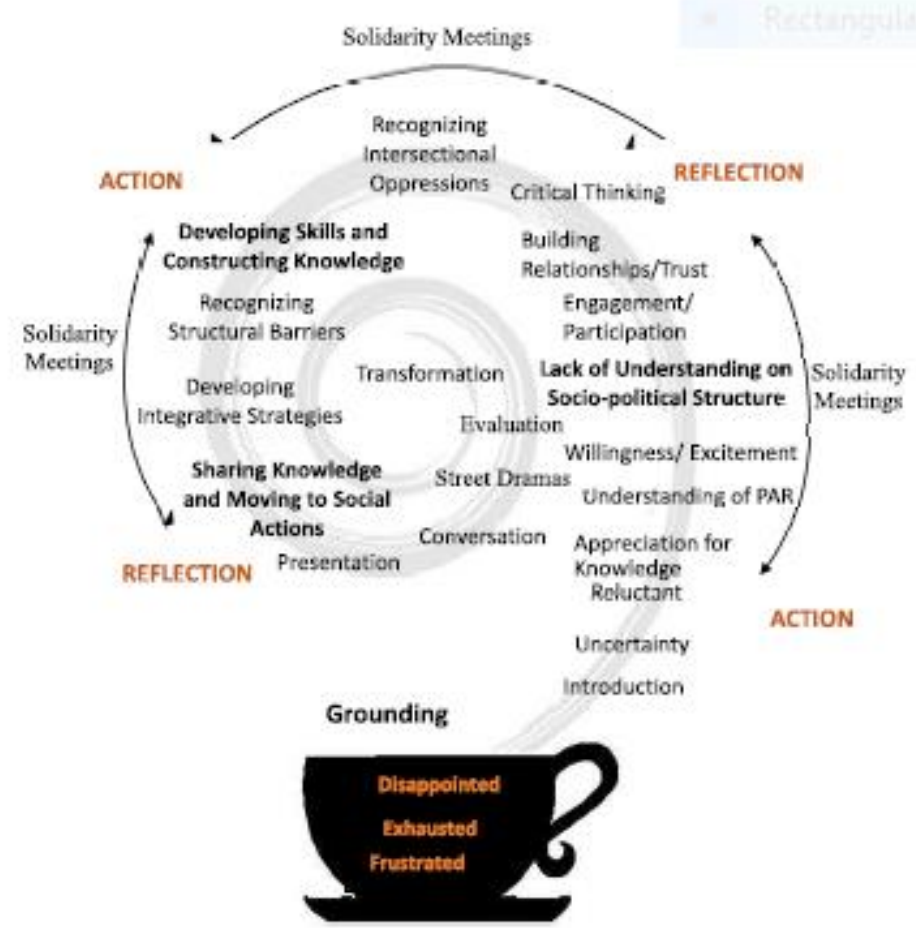

Figure 1: Action-Reflection-Action: The Figure Demonstrates the Progress and the Summary of the Integrated Phases of our Liberatory Journey

The following section will provide a consideration of those four dimensions.

\section{Grounding Context}

The grounding context phase examines how we, as co-researchers, began our liberatory journey. When we found that a researcher from Canada was coming to work with us in our reintegration, it did not initially capture our interests nor was there unbridled excitement about being a part of the project. We had been the subject of academic interest before and had experienced disappointment and frustration. Indeed, we were not sure what she would be asking us - we were already exhausted by giving interviews about our trafficking experiences - and felt exploited in our commodification as research objects. However, we decided to attend a sharing session on the project, where we learned not only about PAR but also gained an increased understanding of our potential roles and responsibilities in the study. In the beginning, the room was very quiet with senses of fear and trepidation, but we also had lots of curiosity. The researcher consciously broke the silence by saying:

Upon doing research on safe migration, I visited more than 40 brothels in Delhi in 2004. In the beginning, I started my conversations with the Nepalese women 
in Hindi and in a few minutes, I, unintentionally, spoke to them in the Nepali language which significantly changed the dynamic of our conversations as they were very friendly and open to talk more. For instance, a woman who had told me five minutes ago they were happy in brothels as they were making money and also sending money to their families in Nepal, asked me with eyes full of tears to take them with me. While we were talking in our language, the madam of the brothel got suspicious, and once she found that I was also from Nepal, she became very upset and immediately asked me to leave the brothel and sadly, I left the building with my eyes full of tears. While I was leaving, one woman asked me if I would come back to take them from the place. I indeed felt very helpless, hopeless and of course vulnerable. I was angry then. I still am now. However, while their voices are still echoing in my ears, I have never gone back to the brothels to help them out. Therefore, I would like to work together with the women who had similar experiences as the women I met in the place and provide them with an opportunity to empower themselves.

When she shared how her experience visiting brothels in India inspired her to undertake this study, we became more at ease. Moreover, as we shared our strengths and aspirations in an introductory session, we found this helped us become more comfortable and trusting. On behalf of the group, one of us said:

There are so many researchers who come from different countries to conduct research on trafficking issues. We were often asked to share our experiences in trafficking with a focus on brothels, and this makes us feel angry. We absolutely do not want to be interviewed for or support this type of research.

In responding to our uncertainties and reluctance, the researcher claimed that PAR was unique in its transformative nature as it promotes a democratic process of knowledge construction. The researcher assured us by saying the study would not ask us to share our experiences on trafficking, as the goal of the study was to explore the collective voices of our reintegration and promote our personal transformation. We were surprised by the researcher's responses when she further said:

I will not ask you to talk about your experiences in trafficking. You are a driver in this project, so I am totally fine with wherever you want to take your bus and choose a destination. I know you have lots of knowledge and skills and I believe in your abilities and capacities which will definitely take you to that destination. I just wanted to provide you with an experiential learning opportunity for your personal and professional growth. Please keep in mind that you will be playing roles of co-researchers and you will not be used as participants or research objects of the study.

Surprisingly, this was the first time we felt appreciated and approached for our knowledge and experiences from a participatory angle, and this motivated us to get to know the researcher and learn more about the project. We then asked Rita to help us further understand what PAR was, and provide more specifics such as: what a PAR process would look like in our context, what the shared responsibilities of researchers and co-researchers actually means, and the anticipated length of the study. By recognizing the opportunity to learn and the crucial importance of our involvement in the project, we became excited and expressed our willingness to become more directly involved in the collective journey.

Our journey continued with the next meeting, which provided a space for developing the collective learning principles for our work as a group. This process clarified our roles and offered an opportunity for all of us to speak, especially those who were not usually comfortable speaking in a group. Additionally, as 
the project progressed, and through the use of a number of ice breaking and team building exercises, such as "Ball of Yarn, and, "True or False", we built our relationships among the research group, which led to meaningful conversations and dialogues (Dhungel, 2017d). The researcher invited us to reflect on a time and moment that made us cheerful. The room was silent as for many of us this was the first time someone seemed to be interested in learning about our happiness and enjoyable times. Therefore, we were not sure what we should or should not be sharing, and one of our team members noted:

I am used to sharing my pain and tragedy of my life with families, friends and researchers who came from abroad and some from here in Nepal. No one had expressed their interests in learning my happiness and joy yet. Hence, I am not sure what you want us to tell you.

However, the exercise, in fact, helped us understand that there are always two sides of the coin. We thought that we had only darkness in our lives and we never had the opportunity to explore the brighter side, which is also present in our lives. For example, one of us shared that because of the exercises she recognised that she also could smile, laugh and also have an enjoyable time as others do. The process was beginning to help us to feel and understand that we were more than trafficking survivors; we were people with hopes, dreams and ideas. The process was helping us to become fully human and realised that we were not different from others.

In addition, to consider the joys of our common experiences, we also enhanced our knowledge of PAR and its different approaches, which allowed us to consider the applicability and value of different tools and methods for our own liberatory journey, such as solidarity group meetings, peer interviews, interviews with stakeholders and educational campaigns. The following section will assess the different tools and the process used for the next phase centring on the areas of consciousness-raising and knowledge construction.

\section{Critically Understanding Socio-political Environment}

This second phase focuses on consciousnessraising related to how the prevailing social, cultural and economic environment increases our vulnerability to trafficking and associated problems with reintegration. As time progressed, we found we were deeply engrossed in the inquiry process, allowing us to develop critical thinking and analytical skills relating to our intersecting oppression. Before getting involved in the study, for instance, due to the lack of understanding of the socio-political structure and socially constructed factors escalating our vulnerability in reintegration, we believed that we did not "fit" in society and thus accepted our oppression as normal and understandable. In fact, we thought this was the result of "Karma" (we did something wrong in our previous lives). However, in group meetings (we had 29 group meetings), we had an opportunity to critically talk about our reintegration issues and identified factors making us doubly victimised in reintegration, including lengthy prosecution systems, limited enforcement of reintegration laws and policies, and victim-centred approaches in program development to support reintegration. Through this, we came to recognise that we should not blame ourselves for our vulnerability. Through PAR we became empowered, and are now able to understand and analytically critique structural domination and exploitation. This helped us redirect blame from ourselves to the oppressive and unjust system. In fact, we are now aware that our oppression is largely located within a broader social and political context, and we also learned the emancipatory fact that inequalities and intersectional oppression are not natural; therefore, the ideals and practices of the oppression can (indeed, must) be both challenged and changed. We can proudly claim that "it is not our fault for being trafficked, so we are entitled to live with respect and dignity as others". Likewise, one of us shared: 
I always shamed myself before my involvement in this study and felt guilty for being who I am. Look at me now I am a completely different person. I can talk to people. I am not shy anymore. I have no fear in saying the right things, and I know how to answer to the people who are against us.

One of us echoed her and narrated:

I do not believe what changes I recently found in me. For the first time in my life, I went myself to interview people, [one of the data collection methods chosen for the study] guess what... I went to the Ministry of Women Children and Social Welfare and interviewed two staff. I also performed street dramas in many places and facilitated a group discussion ... I had underestimated my abilities...and this research helped me to recognise my own talents/skills and supported me to build trust in me and. now I believe I can do anything if opportunities are given

\section{Developing Skills and Constructing Knowledge}

The following section provides an overview of how we developed our research and community building skills and constructed knowledge of our own issues regarding the reintegration of trafficking survivors. As shared earlier, when we raised our consciousness of the broader environment that make us more vulnerable in the process of reintegration, we collectively considered and developed integrative strategies to address the identified and socially constructed root causes of trafficking and the challenges we continue to face in the posttrafficking period. Simultaneously, we conducted peer interviews, followed by interviews with seventeen stakeholders including the Ministry of Women Children and Social Welfare, Nepal Police, Shakti Samuha, Maiti Nepal, Serve Nepal, the media, elected officials, members of the legal profession, and educators to understand their perspectives on the reintegration of trafficking survivors and of the effectiveness and efficiency of their individual programs.
We ourselves developed questionnaires for both peer interviews and interviews with other stakeholders, although we had previously thought we would not be able to do that task as we were not educated in the same formal academic sense as our researcher. However, she encouraged and supported us by saying:

I do not doubt your abilities in developing questions for interviews. You lived through this life and you know what questions we should ask them. You just need to recognize your capacities and skills and tell yourself you can do it.

Most of us had never received such encouragement in our life, and this made us think that we might be able to do it and we should give it a try. Surprisingly, given our initial hesitation, after an hour we each came up with ten questions to share with the group, and finally, after a collaborative process, we picked nine questions for the interviews. Using the questions, we interviewed each other, and this process of looking at the "validity" (and value) of the questions helped to further build our relationships and provided increased opportunities to learn from each other in a respectful dialogue. One of us shared:

Once I heard one of our group member's story I started thinking my pain is nothing in front of her. Although we all are survivors, our stories are different, and I thought I am not the only one who went through the difficulties. We all have the same pain regardless of our stories. However, I learned today that we had lots of similarities and lots of differences.

After conducting initial interviews with stakeholders, we reflected on the appropriateness and effectiveness of the selected questions and made adjustments to the questionnaires, as well as analysed the initial data. While enhancing our practical research skills, we also recognised that it was equally important to have confidence and experience in facilitation skills for both our personal and professional lives and, building on this, some expressed a willingness to facilitate the next 
solidarity group meeting. We then had opportunities to facilitate and co-facilitate meetings, which helped us understand the principles of facilitation and its application in practice. This added to the diversity of skills in our group toolbox. Overall, through actionreflection-action, we generated our knowledge of our common issues in reintegration, developed strategies to address the issues and, finally, moved towards a range of social action, directed at a number of targets and audiences. The following section will discuss how we shared constructed knowledge with a variety of communities and moved towards transformative work in social action.

\section{Sharing Knowledge and Moving to Social Actions}

The fourth phase of our transition from oppression to liberation centres on the different approaches we used for knowledge-sharing and advocacy. With an increased recognition as to how male-dominated society and oppressive structures have increased our vulnerability to trafficking and hindered our reintegration, we developed a number of educational strategies to reach out to oppressors and perpetrators so we could share our findings/stories, and interact with them in multiple ways. Through this process, we also wanted to reach to the broader, uninformed public. Most importantly, perhaps, was our participation in collective actions targeted at the social and political levels to fight the structures and systems that marginalise and oppress us. This was a very powerful phase of our journey. We, who were mostly silent and passive gained opportunities to raise our voices, and we become active and vocal agents for social change. For instance, the research group including researcher and co-researchers initiated our social campaigns by presenting our stories through conversation cafes, interactive sessions and street dramas in a number of places. Surprisingly, many elected officials, police officers, educators, community leaders, the media and children participated in these activities. This spoke to not only a recognition of the importance of the issue but also of the ability to work with allies to create a new alternative movement. Notably, the drama, especially the words and the acting, made the audience laugh and provided them with both education and entertainment. However, as the drama progressed towards some more sorrowful and disheartening scenes, many in the audience got tears in their eyes, and they later told us that some scenes wrenched their hearts and made some of them angry. Once the drama finished with a happy ending everyone gave us a big round of applause, which left us in tears. Following the drama, some of the co-researchers interviewed an elected official, a police official, teachers and some community residents from the audience for their reflections on the drama. In addition, we also distributed an evaluation form to the participants and asked them to share their learnings and reflections stemming from the drama. We learnt that the various communities received the drama very positively, and it was able to start the transformative dialogue within communities about their perceptions of the survivors of trafficking (Dhungel, 2017d).

During this process, one of us shared:

I think we did achieve our goals more than 100 per cent as I never thought we would have so many people in the audience for the drama and lots of participants for interactive sessions as well. After the drama, one of the women living close to my house came to me and said "please forgive me for all that I did to you. I know I treated you very badly when you came back from India, and now you are the one who was able to open my eyes. If I had not come to watch this drama, I would not understand what you folks are going through and what can be done [the woman is a neighbour of one of the co-researchers].

During subsequent campaigns, we created "guiding principles for interviews" for the media when they approach us for interviews. In June 2017, we also wrote a recommendation letter to the Government of Nepal's Ministry of Women, 
Children and Social Welfare on what they could do to support effective and dignified reintegration. Overall, with the vision of personal and social change, together with concrete examples in practice, the PAR process (please refer to Figure 1) demonstrates that we oppressed people are no longer clients, and if we get an equal opportunity to raise our voices and develop skills and knowledge, without any doubt, we will become agents of transformative change and inclusion. Figure 1 clearly shows our action-reflection-action process of the collaborative journey for transformative change.

\section{Pathways to Liberation}

As noted earlier, through the action-reflectionaction process we recognised that our collaborative journey transformed us at both the personal and collective levels. However, the pathway from oppression to liberation was challenging for us. Remarkably, despite the difficulty of the task and process, on the one hand, we challenged the power of the oppressive culture, and on the other hand, we invited communities to become allies and walk with us to address the various and complex issues relating to trafficking and reintegration of trafficking survivors. As shown in Figure 2 , as the process evolved, we assessed our outlook and state of mind in both our oppressed and liberated states. Certainly, that does not mean we do not still experience aspects of oppression in our lives, but we are now more empowered and confident, and we are not ashamed of our past. Our society needs to know that we do not want to live trapped in the personal and structural oppression of our past, and we have already moved on in terms of healing and growth through peer interviews, art therapy and performative actions, such as street dramas and interviews with stakeholders. We believe that Figure 2 below will help demonstrate what living in oppression is actually like and, subsequently, what liberation means to us (Figure 3). We are people just like everyone else. We have proved that we survivors are no different from dominant people.

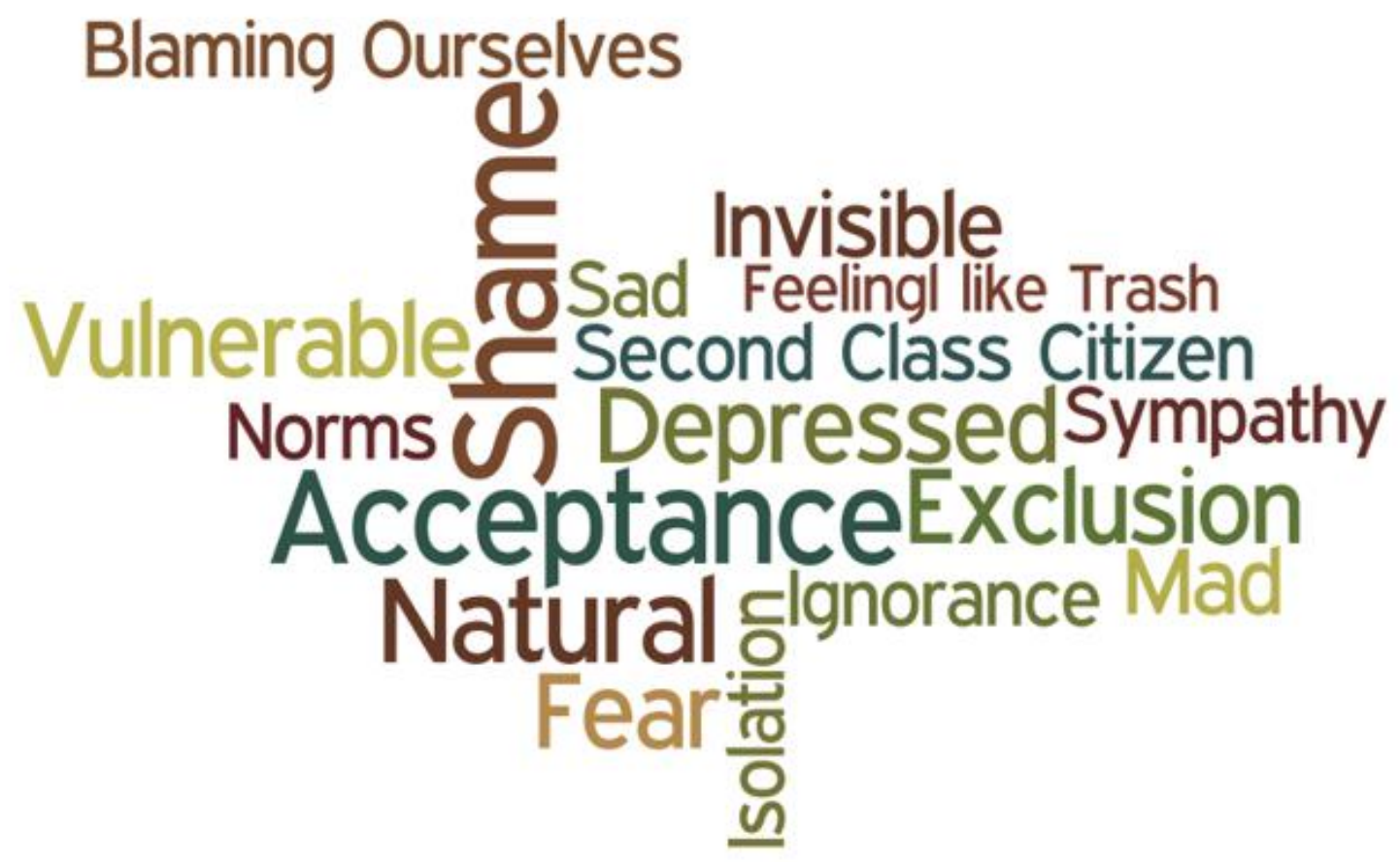

Figure 2 Oppression: This Figure Reveals our Thoughts and State of Mind of an Oppressive Culture 


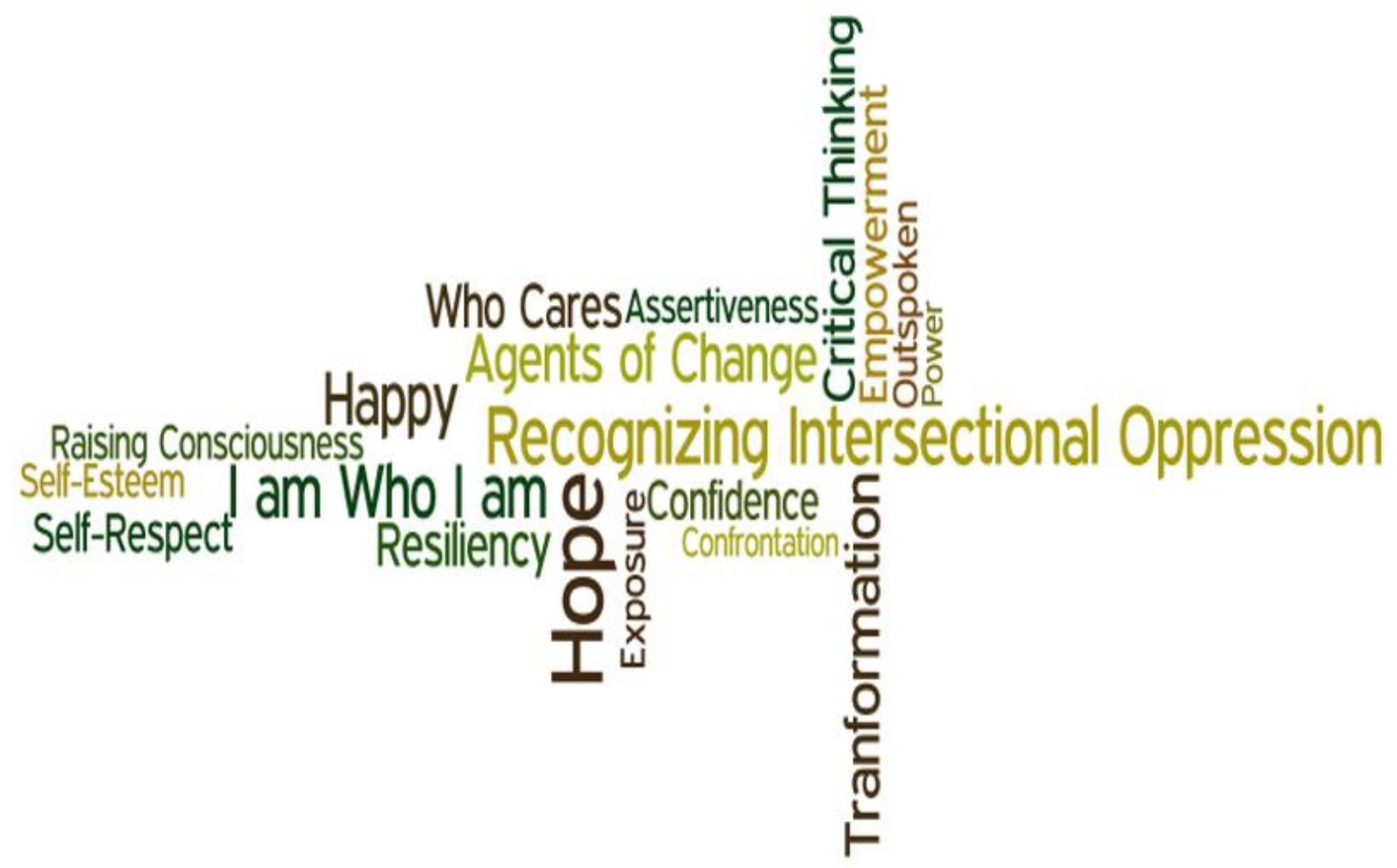

Figure 3 Liberation: This Figure Depicts our Outlooks and State of Mind in a Transition of Oppression to Liberation

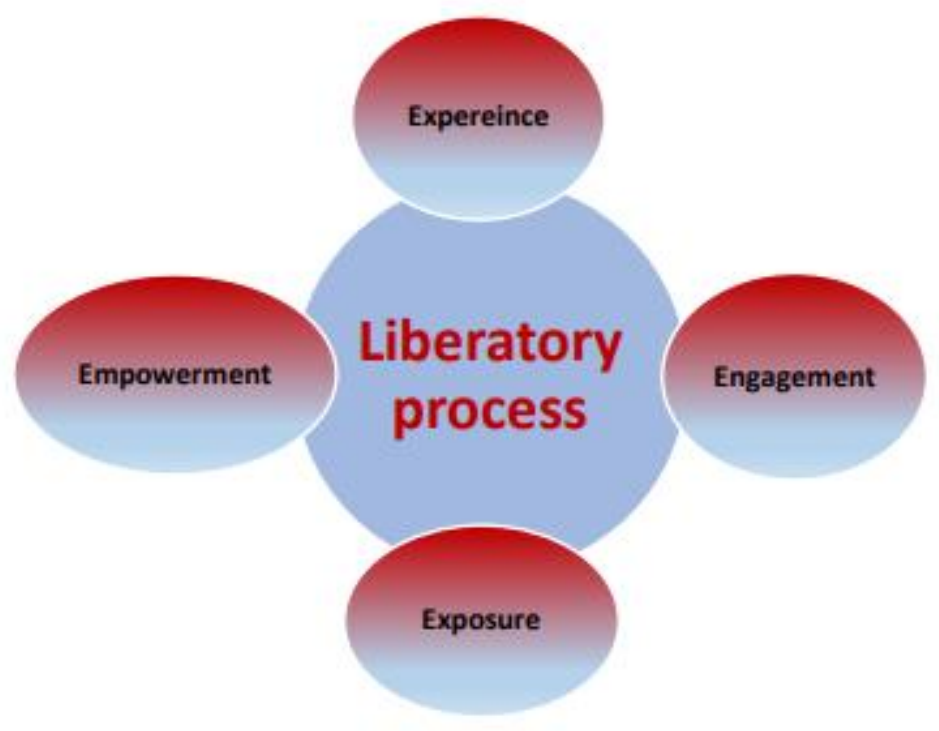

Figure 4: "4Es" Practice Model: Steps towards Liberation Source: Adapted from Winderdyk \& Dhungel (2018)

\section{Emerging Liberatory Practice Model}

The following section provides an overview of the "4Es" of the anti-oppressive approach
(Experience, Engagement, Exposure and Empowerment) we developed, based on the theoretical frameworks (Cordo \& Hill- Rodriguez, 
2017; Wagaman, 2011; Winderdyk \& Dhungel, 2018) with a vision that this would support trafficking survivors in their journey towards liberation and, perhaps, an approach that could be used more widely, especially while working other disenfranchised populations who do not usually get the same opportunities we ourselves received from working on this project. Based on our experiences in the study process, we came to recognise that our core involvement in research, program and policy development and evaluation is critical. If we are to have effective public policy and program, it is essential that people - not only bureaucrats and conventional academics - are centrally involved in the policymaking and program development process. Therefore, representatives of dominant groups need to understand that if they are coming to us for access to our information, and are willing to work with us on the basis of that information, the necessity of advancing our own personal transformation and emancipation should be solidly integrated into their research production agenda. As shown in Figure 4, we developed an emerging " $4 \mathrm{Es}$ " practice model for our liberation on foundations suggested by (Cordo \& HillRodriguez, 2017; Wagaman, 2011; Winderdyk \& Dhungel, 2018 ) and, based on the growth we experienced, we highly encourage dominant groups to apply this model in their practice and research.

\section{Experience}

Experiences, both good and bad, reflect our unique expertise and speaks to the subjective and evolving socially and individually constructed reality of situations. We have learned profoundly from our experiences, and by considering and sharing our experiences in the process of this project, we not only examined our common "individual" stories but also critically understood the working of sociopolitical climates that can make us "doubly victimised" in reintegration. Therefore, by recognising that importance of the survivors' experiences, this helps to create a safe environment that allows people to consider and critically understand their common issues and helps in raising their voices to amplify the importance of their individual and collective experiences. We have found that these experiences inspire people to support others and can prevent them from being (or, even, feeling) victimised. One of us, for example, noted:

I always see things positively. If we were not trafficked, we would not be here together now. Therefore, being a trafficked survivor and having all trafficking experiences has now become my strengths. If I was not trafficked, I doubt if I would be working in antitrafficking practices. I am proud of myself. At least, I am helping those children and women who are not different from me.

\section{Engagement}

Engaging with survivors and building relationships is essential for liberation. Therefore, dominant groups need to understand that they could and should learn from our experiences, but they also need to be cognizant that creating a safe and non-judgmental space for engaging and building relationships with us is equally important. Since we have already lost trust in people, we do not easily engage and share our experiences. As noted earlier, the first day we met with researcher we were not interested in the project, but as we went through the process, she attempted to build relationships and trust through a number of different engagement approaches. She also demonstrated a non-judgmental approach, warmth and empathy. Finally, given time and a positive experience, we accepted her as a member of our community and allowed her to walk with us in solidarity and friendship on our collaborative journey.

\section{Exposure}

However, providing a safe environment to engage with survivors and learn from their experiences is not sufficient, by itself, for liberation. Their exposure to the public is also essential for a collective message and individual 
empowerment. Using our example, by interviewing agencies working in anti-trafficking efforts together with presenting the outcomes of the project and facilitating conversation café to communities, we had a number of opportunities to expose ourselves to a wide range of audiences. This allowed us to know more people and their worldviews about survivors and their reintegration, but more importantly to realise that such exposure made us increasingly more comfortable in a public forum. We want to raise our voices not only in the safe space of interviews or in the security of a closed room, but we also want to go out and talk to the public so everyone can hear our voices, learn from our experiences and work in solidarity for understanding and social change. One of us shared:

I still remember the moment when I was going to interview one of the agencies for this project. I was getting nervous and anxious, so I called the researcher and asked if she could come with me. She came with me, but she encouraged me to interact with people and interview them. Once I had the first interview, guess what for the next time I did go on my own and interviewed them. I got lots of confidence and started believing in my capacities. This is how I started my liberatory journey.

\section{Empowerment}

The process of action-reflection-action helped empower ourselves in multiple ways. The level of our participation in this project, especially the street dramas, was highly empowering and powerful. By the time we were performing street dramas and interacting with the media, we had already completed a number of different activities that educated us about the social relations of dominant groups, their oppressive culture and the impact of intersectional gender oppressions that serve to make women and children vulnerable to trafficking, and, tragically, escalating survivors' vulnerability in their reintegration. Additionally, by interviewing agencies and facilitating conversation cafes, we learned how "they" constructed the term "successful reintegration" which, not surprisingly, frequently did not align with our definitions of "successful reintegration". This incongruence then gave us more energy to reach out to the public and spell out loudly what reintegration means to us, and ensure our voices were heard and valued through dramas and a press conference. More importantly, as stated above, submitting a recommendation letter to the Ministry of Women Children and Social Welfare is evidence of being empowered. We had a voice and felt the government should hear us.

As suggested by the group, it is important to apply the 4Es approach to social science research, especially in social work education and practice to give voice to their experiences of oppression and liberation. However, this model, undoubtedly, challenges researchers, policymakers and practitioners who tend to use a more conventional approach in both research and practice. This approach demands a commitment of time and challenges the knowledge and academic expertise of scholars and practitioners, which certainly has more power and authority compared to the people who are in oppression. Notably, the time has come to work in social work education for a paradigm shift from "clients as beneficiaries to "clients as partners and agents of change", and to use the proposed approach, especially while working with disenfranchised and marginalised populations.

\section{Moving Forward: Key Messages to Dominant Groups and Oppressors}

During our liberatory journey, we recognised the importance of our voices and involvement to work collaboratively with a wide range of stakeholders, including educators, policymakers and practitioners. Moving forward, we have developed key messages for dominant groups to consider and implement the content in their practice:

- We are no different from others; 
- We are formally uneducated, but we are not ignorant of our intersectional oppression; we have the knowledge, skills and capacity to work for liberation and social change;

- We will not be subject to ongoing judgement based on our past;

- We are resilient - not victims;

- Do not underestimate our power and knowledge;

- You need to trust our abilities and skills;

- Come, as allies, to work "with" us not "on" us

- Provide us with an opportunity to and work collaboratively with a wide range of stakeholders, including educators, policymakers and practitioners; and

- Use the 4 "E's" approach support us in our process of emancipation and promote a just society.

\section{Discussion and Conclusion}

The PAR process supported us in our journey from oppression to liberation. As noted earlier in this paper, by working in solidarity through this liberatory process, we came to understand our intersectional oppression critically, and developed strategies and actions to address the identified issues. Therefore, we claim that solidarity and unity are powerful, and they helped amplify our collective voices to advocate for social change and our emancipation. We were able to collectively draw upon our individual experiences, and work together to build a social movement. We became more comfortable in telling our stories and had confidence in our ability to give voice to what had happened to us, what was happening to us and how we could change this in the future. But this process required us to invite more people to join us on that transformative journey. People listened to our voice but, equally importantly, people got to know us as people and not simply, and inconveniently, as victims worthy of pity, not agents offering hope and solidarity. In our growth, we challenged prevailing ideas of "common sense" and social relations and developed an alternative understanding and a transformative social movement. This was related to us finding our collective voice, and using this to speak passionately and persuasively to willing and open ears.

Essentially, the above process shows the importance of individual and collective capacity building, self-organisation, the building of alliances, broader public exposure of social issues and the central role that the people themselves must play in the development of both transformative social policy, and inclusive and participatory communities. It is not a linear process and sometimes it is messy. However, it results in us all becoming more fully human. Therefore, researchers, practitioners and policy/program makers are required to recognise the essential need for inviting people who are in oppression to work together with them and create safe and democratic environments for them to engage in critical dialogues which can support them to contribute to decisions that have an impact on their lives. Their lived experiences make them experts in their lives, and thus they should not be treated as clients/beneficiaries - they are truly agents of transformative change and inclusion - and that critical understanding can help people move from oppression to a path of liberation. Voices have been raised and now ears need to be opened.

\section{References}

Agger, B. (2006). Critical social theories: An introduction. New York, NY: Paradigm.

Boal, A. (1979). Theatre of the oppressed. New York, NY: Theatre Communications Group.

Buet, L., Bashford, P., \& Basnyat, M. (2012). Looking forward to tomorrow: A study on the reintegration of trafficking survivors. Kathmandu, Nepal: Asha Nepal, Terra des homes Foundation and Shakti Samuha.

Cameron, S., \& Newman, E. (2008). Trafficking in human: Social, cultural and political dimensions. New York, NY: United Nations University Press. 
Chaulagai, P. (2009). Trafficking survivors in Nepal: An exploratory study of trafficked women's experiences and perceptions of their reintegration (Master's thesis).

Retrieved from

https://bora.uib.no/bitstream/1956/3471

/1/58332708.pdf

Chen, C., \& Marcovici, K. (2003). Exploring the status of reintegrated girls: $A$ participatory study, Kailali and Kanchanpur, Nepal. Kathmandu, Nepal: Save the Children US.

Cord, J, \& Hill-Rodriguez, D. (2017). The evolution of a nursing professional practice model through leadership support of clinical nurse engagement, empowerment, and shared decision making, Nurse Leader, 15 (5), 325-330.

Depoy, E., Harman, A., \& Haslet, D. (1999). Critical action research: A model for social knowing. Social Work, 44(6), 560-569.

Dhungel, R. (2017a). Transformative impacts: Trafficking survivors for sexual exploitation and their involvement in an emancipatory study in Nepal. Asia Pacific Journal of Advanced Business and Social Studies, 3(1), 318-328.

Dhungel, R. (2017b). "You are a besya" Microaggression experienced by trafficking survivors exploited in the sex trade. Journal of Ethnic and Cultural Diversity of Social Work, 26(1/2), 126-138.

Dhungel, R. (2017c). A Critical approach: A comprehensive analysis of socially constructed factors for trafficking of women in Nepal, Perspective on Social Work Journal, 13(1), 31-41.

Dhungel, R. (2017d). Reintegration of trafficking survivors in Nepal. Doctoral Unpublished Dissertation. University of Calgary. Canada.

Dominelli, L. (2002). Anti-oppressive social work theory and practice. Hampshire, UK:

Palgrave, MacMillan.
Fals-Boarda, O. (1988). Knowledge and peoples' power. New Delhi, India: Indian Social Institute.

Fals-Boarda, O. (1979, March). Investing reality in order to transform it: The Columbian experience. Dialectic Anthropology, 4, 3335.

Frederick, J., Basnyat, M., \& Aguettant, J. L. (2010). Trafficking exploitation in the entertainment and sex industries in Nepal: A handbook for decision makers. Kathmandu, Nepal: Terra De homes Foundation.

Frederick, J. (2005). Status of support, care and reintegrating of trafficked persons in Nepal as of December 2005. Tulane Journal of International and Comparative Law, 14, 317-330.

Freire, P. (1970). Pedagogy of the oppressed. New York, NY: Seabury Press.

Hoare, Q., \&Smith, N. G. (1999). Selections from the prison notebooks of Antonio Gramsci. New York NY: International Publishers.

Hennink, M., \& Simkhada, P. (2004). Sex trafficking in Nepal: Context and process. Retrieved from http://stanford.edu/class/humbio129s/cgi bin/blogs/marginalizedpop/2009/05/21/s ex-trafficking-in-nepal/comment-page-1/

Herr, C., \& Anderson, G. L. (2005). The action research dissertation: A guide for students and faculty. Thousand Oaks, CA: Sage.

Hoffman, M. (1987). Critical theory and interparadigm debate. Journal of International Studies, 16(2), 230-249.

Locke, R. A. (2010). Rescued, rehabilitated, and returned: Institutional approaches to the rehabilitation of survivors of sex trafficking in India and Nepal (Master's thesis). (UMI No. AAT 1478251). Available from ProQuest Dissertations and Theses Database 
(http://proquest.umi.com.ezproxy.lib.ucal gary.ca)

McNeill, L. A. (2008). The price of a life:

Legislating sex work and trafficking in Nepal (Doctoral dissertation). Retrieved from, http://www.angelfire.com/me3/leila3/TH ESIS_secure.pdf

McTaggart, R. (1991). Principles for participatory action research. Adult Education Quarterly, 41(3), 168-187.

Mullaly, B. (2010). Challenging oppression and confronting privilege. Don Mills, ON, Canada: Oxford University Press.

Mullaly, B. (1997). Structural social work: Ideology, theory, and practice (2nd ed.). Don Mills, ON, Canada: Oxford University Press.

Park, P. (1993). What is participatory research? A theoretical and methodological perspective. In P. Park (Ed.), Voices of change: Participatory research in the United States and Canada (pp. 1-19). Toronto, ON, Canada: OISE Press.

Reason, P., \& Bradbury, H. (Eds.). (2006). Handbook of action research. London, UK: Sage.
Sagris, J. (2008). Liberatory education for democracy. The International Journal of Inclusive Democracy, 4(3), 1-4.

Shakti Samuha. (2013). Shakti Samuha Annual report 2013. Kathmandu, Nepal: Shakti Samuha.

Sharma, P. (2014). Reintegration of victims and survivors of trafficking in Nepal. (Master's Dissertation). Retrieved from, http://soar.wichita.edu/bitstream/handle /10057/10977/t14031_Sharma.pdf;seque nce $=1$

Wagaman, M. A. (2011) Social empathy as a framework for adolescent empowerment, Journal of Social Service Research, 37(3), 278-293.

Winterdyk, J., Perrin, B., \& Reichel, P. (2012). Introduction. In J. Winterdyk, B. Perrin \& P. Reichel (Eds.), Human trafficking: Exploring the international nature, concerns, and complexities research in the United States and Canada (pp. 1-17). New York, NY: CRC Press.8).

Winderdyk, J., \& Dhungel, R. (2018). Migrant Smuggling in Canada: Possible Lessons for Beyond Borders. Journal of Criminalistics and Law, 23(3), 211-231. 